\title{
Comparison of State Medical Licensing Board Disclosures Regarding Resident Performance for United States Allopathic, Osteopathic, and Foreign Medical Graduates
}

Michal Gajewski, DO; Machteld Hillen, MD; Daniel Matassa, MD; Anastasia Kunac, MD; Michael Anana, MD; Lisa Pompeo, MD; Neil Kothari, MD; Tiffany Murano, MD

From the Departments of Anesthesiology (Dr Gajewski), Neurology (Dr Hillen), Internal Medicine (Drs Matassa and Kothari), Surgery (Dr Kunac),

Emergency Medicine (Drs

Anana and Murano), and Obstetrics, Gynecology, and Women's Health (Dr Pompeo)

at Rutgers New Jersey Medical School in Newark.

Financial Disclosures: None reported.

Support: None reported.

Address correspondence to Matcheld Hillen, MD, Rutgers New Jersey Medical School, 90 Bergen Street, DOC 5200 Newark, NJ 07103-2757.
Context: While recent streamlining of the graduate medical education process signals an important change from the traditional dichotomy between doctors of osteopathic medicine (DOs) and US-trained doctors of medicine (USMDs), this new uniformity does not continue into the process for licensure, including state medical licensing verification of training (VOT) forms for DOs, MDs, and foreign medical graduates (FMGs). Wide variability remains.

Objective: To document the differences in the performance metrics program that directors are required to disclose to state medical licensing boards for DOs and FMGs compared with USMDs.

Methods: VOT forms were collected from all osteopathic and allopathic licensing boards for all US states, Washington DC, and US territories. The authors then reviewed VOT forms for questions pertaining to trainee performance only in states where VOT forms differed for DOs, USMDs, and FMGs. Licensing board questions were categorized as relating to disciplinary action, documents placed on file, resident actions, and nondisciplinary actions by the program.

Results: Fifty-six states and territories were included in the study (50 US states; Washington, DC; and 5 US territories). Most states and territories (46; 82.1\%) used the same VOT form for DOs and USMDs. All states and territories except New York used the same form for FMGs and USMDs (55; 98.2\%). Of the 14 states with an osteopathic board, Nevada used Federation Credentials Verification Service (FCVS) for DOs only, and 8 states used a unique osteopathic VOT form. Of these 8 osteopathic boards, 3 VOT forms did not ask any questions regarding resident performance during training. Of the remaining 5 forms, all asked about disciplinary actions. Ten states and 1 territory (US Virgin Islands) required the FCVS for both USMDs and FMGs, but not for DOs, while New York required FCVS only for FMGs. Nevada required FCVS only for DOs.

Conclusion: Although VOT requirements for FMGs and USMDs were mostly the same within states, performance metric question sets varied greatly from state to state and within states for osteopathic vs allopathic licensing boards. Implementation of a standardized VOT form for all applicants that includes academic performance metrics may help ensure that medical licensure is granted to all physicians who demonstrate academic competency during training, regardless of their degree.

J Am Osteopath Assoc. 2020;120(12):871-876. Published online November 2, 2020. doi:10.7556/jaoa.2020.152

Keywords: allopathic physician, foreign medical graduate, medical licensing board disclosures, osteopathic physician, verification of training 


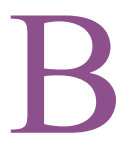

efore the 2020 National Resident Matching Program (NRMP), US-trained allopathic physicians (USMDs) could only apply to residency programs accredited by the Accreditation Council for Graduate Medical Education (ACGME), while doctors of osteopathic medicine (DOs) could apply to either ACGME or American Osteopathic Association (AOA) accredited residencies. Since 2012, the ACGME, the AOA, and the American Association of Colleges of Osteopathic Medicine (AACOM) have been transitioning to a single accreditation system for graduate medical education (GME). This collaboration was a response to the 2011 ACGME Common Program Requirements, which would have restricted DOs and foreign medical graduates (FMGs) from Canadian-accredited programs from entry into ACGME accredited programs if they did not complete their entire residency training at an ACGME program. ${ }^{1}$ Although the overall number of both US citizen and non-US citizen international medical graduates (IMGs) registering for the NRMP has decreased, the 2019 match brought an all-time high in DO candidates submitting a rank order list. ${ }^{2}$ Since 2015, the number of DO candidates seeking positions through the NRMP has risen by $103 \% .^{3}$ As the NRMP is now the only option for all applicants, that number will surely increase again.

While the single GME process signals an important change from the traditional dichotomy between DOs and USMDs, this uniformity does not continue into the state medical licensure process. Despite the standardization of residency training requirements, there remains wide variability in the way physicians obtain medical licensure. With 70 medical licensing boards across the US and its territories, requirements for medical licensure depend upon the type of degree (DO vs USMD vs FMG), medical school accreditation (Liaison Committee on Medical Education [LCME] vs Commission on Osteopathic College Accreditation [COCA]), and whether there is an osteopathic licensing board in the state.
In a previous study by this research team, ${ }^{4}$ we evaluated the program directors' (PDs) disclosure requirements regarding GME academic performance of USMDs on state medical licensing verification of training (VOT) forms. The ACGME core competencies provided a framework for assessing academic performance and ensuring high-quality care for patients. The previous study ${ }^{4}$ revealed that none of the allopathic licensing boards across the US and its territories used the 6 ACGME core competencies to determine candidature for licensing. We also identified a lack of homogeneity in the information requested from PDs by individual states and an overall focus on disciplinary actions rather than academic performance on VOT forms. ${ }^{4}$

This study's objective was to determine what PDs are mandated to disclose regarding the academic performance of DOs and FMGs and compare these findings with PD disclosure requirements for USMDs.

\section{Methods}

This study was granted exemption from review by the institutional review board at Rutgers University. An online search of VOT forms for DOs, USMDs, and FMGs was performed by a team of current and former PDs and educators from 6 different medical specialties (M.G., M.H., D.M., A.K., M.A., L.P., N.K., T.M.). We obtained VOT forms from 56 medical boards in all 50 US states, Washington, DC, and US territories (Guam, US Virgin Islands, Northern Mariana Islands, American Samoa, and Puerto Rico), and 14 DO boards (Arizona, California, Florida, Maine, Michigan, Nevada, New Mexico, Oklahoma, Pennsylvania, Tennessee, Utah, Vermont, Washington, and West Virginia) in May 2019. Notation of the optional or required use of the Federation Credentials Verification Service (FCVS) by each state board was made, and we noted whether different VOT forms were required for DOs or FMGs. Researchers confirmed with the medical licensing board via email or telephone in circumstances when the VOT form could not be located using an online search. 
We reviewed VOT forms for questions about trainee academic performance only in states where VOT forms differed for USMDs, DOs, and FMGs. We defined academic performance as the level of achievement in the 6 core competencies. The VOT questions from all forms were collected and categorized as follows: disciplinary actions, documents placed on file, actions taken by residents, and nondisciplinary actions taken by the program. Questions were categorized as "disciplinary actions" if they queried whether the applicant had ever been formally disciplined, placed on probation, dismissed, suspended, had privileges restricted, was terminated, expelled, asked to resign, removed from patient care, investigated or placed under investigation, or if they had adverse charges or reactions. Questions were categorized as "actions taken by residents" if they queried whether the trainee had taken a leave of absence or break during training, requested to be transferred from the program, or had any unexcused absences. Questions categorized as "nondisciplinary actions taken by the program" related to remediation, partial credit, extra training, nonpromotion, and nonrenewal. The final category, "documents placed on file," included questions regarding negative reports or documents related to limitations or special requirements. In the instances where FCVS was optional, only data from the state's own VOT form were included.

A data abstraction form was created and used to tally the results. There was an agreement of all categories by 3 authors (T.M., M.H., N.K.) before data collection. Blank abstraction forms were given to 2 authors (D.M., M.G.) who reviewed all VOT forms and application requirements independently; their results were compared. This data was then confirmed by 2 independent reviewers (M.H., T.M.) and all discrepancies were jointly resolved. States or territories that had either licensure forms with no questions regarding resident performance or had no VOT form were also noted. Questions about mental health and substance use disorders were not included in this review. Data obtained from the review of the VOT forms for DO and FMG's was compared with that of USMDs.

\section{Results}

The study's total sample included 56 US states and territories (50 US states; Washington, DC; and 5 US territories). The FCVS is currently accepted by 45 of 56 allopathic medical boards and 12 of 14 osteopathic boards; only 12 states/territories mandate it for USMDs, 13 for FMGs, and 2 for DOs. Ten states and 1 territory (US Virgin Islands) required the use of FCVS with its own standardized VOT form for all USMDs, DOs, and FMGs. New York was the only state that mandated the use of the FCVS VOT for only FMGs, while Nevada mandated it only for DOs. The FCVS VOT form asked questions about probation, investigation and disciplinary action (disciplinary actions), negative reports or documents related to limitations or special requirements (documents placed on file), and whether the applicant took a leave of absence or break in training (resident actions). Most states and territories $(46 ; 82.1 \%)$ used the same VOT form for DOs and USMDs.

A total of 70 forms were analyzed: 56 medical boards and 14 DO boards. Fourteen of 56 states or territories (25\%) had an osteopathic board; 8 (14.2\%) of these used a unique osteopathic VOT form (Table 1). These unique osteopathic boards' VOT forms, similar to the FCVS VOT form, asked questions about disciplinary action taken against the resident (5 of 8 ; $62.5 \%)$, resident actions $(3 ; 37.5 \%)$, documents placed on file $(1 ; 12.5 \%)$, and nondisciplinary actions taken by the program, specifically regarding contract nonrenewal $(1 ; 12.5 \%)$. Of the 8 states with osteopathic boards with their own form, 2 VOT forms (25\%) only required training dates and $1(12.5 \%)$ only asked for an "overall evaluation." The other forms contained questions about probation or leave of absence ( 3 of 8 ; $37.5 \%$ ); questions about investigation, discipline, or restrictions ( 2 of $8 ; 25 \%$ ); and questions about adverse action, limitation, negative reports or nonrenewal (1 of $8 ; 12.5 \%)$. No specific questions were asked about academic performance on any of these VOT forms.

The Nevada and Utah osteopathic boards required FCVS; Utah required FCVS for all osteopathic and 


\section{Table 1.}

Summary of Findings in States with an Osteopathic Medical Licensing Board

\begin{tabular}{|c|c|c|c|c|c|c|c|c|}
\hline \multirow[b]{2}{*}{ State } & \multirow[b]{2}{*}{$\begin{array}{l}\text { Unique } \\
\text { DO VOT }\end{array}$} & \multirow[b]{2}{*}{$\begin{array}{l}\text { Same } \\
\text { VOT as } \\
\text { USMDs }\end{array}$} & \multirow[b]{2}{*}{ FCVS } & \multicolumn{4}{|c|}{ Any questions asked on the VOT form regarding: } & \multirow[b]{2}{*}{$\begin{array}{c}\text { No } \\
\text { Questions }\end{array}$} \\
\hline & & & & $\begin{array}{c}\text { Disciplinary } \\
\text { Actions }\end{array}$ & $\begin{array}{l}\text { Documents } \\
\text { placed on file }\end{array}$ & $\begin{array}{c}\text { Resident } \\
\text { Actions }\end{array}$ & $\begin{array}{l}\text { Actions taken by } \\
\text { the program } \\
\text { (other than } \\
\text { disciplinary) }\end{array}$ & \\
\hline Arizona & $x$ & & & $x$ & & $x$ & & \\
\hline California & $x$ & & & & & & & $x$ \\
\hline Florida & $x$ & & & & & & & $\mathrm{x}$ \\
\hline Maine & & $x$ & & & & & & \\
\hline Michigan & & $\mathrm{x}$ & & & & & & \\
\hline Nevada & & & $x$ & $x$ & $x$ & $x$ & & \\
\hline New Mexico & $x$ & & & $x$ & & & & \\
\hline Oklahoma & & $x$ & & & & & & \\
\hline Pennsylvania & $x$ & & & $x$ & $\mathrm{x}$ & $x$ & & \\
\hline Tennessee & $x$ & & & $x$ & & & & \\
\hline Utah & & $\mathrm{x}$ & $x$ & & & & & \\
\hline Vermont & & $x$ & & & & & & \\
\hline Washington & $x$ & & & & & & & $x$ \\
\hline West Virginia & $x$ & & & $x$ & & $x$ & $x$ & \\
\hline
\end{tabular}

Abbreviations: DO, doctor of osteopathic medicine; FCVS, Federation Credentials Verification Services; VOT, verification of training; USMD, US-trained allopathic physician.

allopathic graduates. Hawaii also uses a different VOT form for DOs and USMDs. Although Hawaii did not have a separate osteopathic medical board, it had a separate DO application which did not contain a VOT form. In contrast, USMD and FMG applications for licensure in Hawaii contained a VOT form that asked 13 questions pertaining to disciplinary actions and actions taken by the program.

In addition to the 8 unique VOT forms mandated by osteopathic boards, there were 2 states (NV, HI) in which DOs had a different VOT form than USMDs. In these 10 states, 6 of the states asked fewer questions, 2 of the states asked the same amount of questions, and 2 of the states ask more questions (Table 2). Nevada uses FCVS for DOs, but not for USMDs. The greatest variation occurred in Hawaii and California, where there were no questions asked for DOs relating to postgraduate training.

\section{Discussion}

Across the 3 pathways to medical degrees (DOs, MDs, and FMGs), our study showed that there was essentially no difference between what PDs were required to disclose regarding academic performance on VOT forms for USMDs and FMGs; however, there was some variability for DOs. Although graduated residents have achieved benchmarks set forth by the ACGME and ABMS, inconsistency exists in the standards by which medical licensing boards grant licensure. Furthermore, there was a lack of standardization of the licensing process as the Tenth Amendment of the US 


\begin{tabular}{lcc}
\hline $\begin{array}{l}\text { Table 2. } \\
\text { Comparison of the Number of Questions Asked } \\
\text { by State's Medical Licensing Boards for USMDs } \\
\text { and DOs }\end{array}$ & USMD & Do \\
State & 5 & 4 \\
\hline Arizona & 10 & 0 \\
\hline California & 0 & 0 \\
\hline Florida & 13 & 0 \\
\hline Hawaii & 2 & 1 \\
\hline New Mexico & 4 & 6 \\
\hline Nevada & 0 & 6 \\
\hline Pennsylvania & 1 & 1 \\
\hline Tennessee & 5 & 0 \\
\hline Washington & 6 & 4 \\
\hline West Virginia & & \\
\hline
\end{tabular}

Abbreviations: DO, doctor of osteopathic medicine; USMD, US-trained doctor of medicine.

Constitution grants this regulation to the states. ${ }^{5}$ As various medical groups began to form around the turn of the $20^{\text {th }}$ century, lobbying campaigns were typically organized by individual stakeholders of the medical profession, such as osteopathic physicians, allopathic physicians, and homeopaths. ${ }^{6}$ Thus, some states formed medical boards depending on which groups were self-promoting while others did not form any. Almost a century later, the Federation of State Medical Boards (FSMB), which oversaw 70 state medical boards (allopathic and osteopathic), attempted to standardize this process by creating the FCVS in $1996 .^{6}$ However, not all states participated, and the FSMB lacked the authority to standardize the process nationally. This lack of a uniform licensing pathway has led to variability between states and within individual states containing both an osteopathic board and an allopathic board.

The findings in this study were comparable with our previous study, ${ }^{4}$ which examined disclosures only for USMDs and showed that medical licensing boards mostly inquired about disciplinary actions and did not inquire about other aspects of their applicants' academic performance, as reflected in the ACGME core competencies. Predominantly, PDs were still required to disclose information about disciplinary actions to licensing boards even though there is currently no published data correlating disciplinary actions in residency to disciplinary actions taken by state medical licensing boards. Papadakis et $\mathrm{al}^{7}$ correlated poor performance on behavioral and cognitive measures during internal medicine residency with a greater risk for state licensing board actions when in practice. Khaliq et $\mathrm{al}^{8}$ examined specific characteristics of disciplined physicians and the nature of the complaints in Oklahoma and found that $25 \%$ of the complaints arose from the quality of care issues, and $18 \%$ were from incompetence. Questions concerning disciplinary action mostly reflect on unprofessional behavior and do not reflect on incompetence and lack of quality of care. While most programs would likely use nondisciplinary actions to mitigate this, as shown in this study and our prior study, ${ }^{4}$ most licensing boards are not collecting such information. Finally, although disciplinary action may indicate that a resident has struggled at some point during their training, it should not disqualify an applicant from obtaining a license to practice medicine.

According to the historic Memorandum of Understanding, the AOA, AACOM, and the ACGME created a single accreditation system to ensure that all residency programs comply with the 6 core competencies and that DOs and FMGs are not limited in obtaining postgraduate training positions. ${ }^{1}$ Since 2010 , the number of DOs in the workforce has increased to $9.1 \%$ in $2018 .{ }^{9}$ Similarly, the number of FMGs who have obtained licenses have also risen, although at a slower pace, to $22.6 \%$ of the present workforce. ${ }^{9}$ PDs must comply with an additional 14 osteopathic licensing boards and an additional 8 VOT forms as DOs continue to make up an increased proportion of trainees.

The state medical licensing boards' mission is to protect the public from incompetent, unprofessional, and improperly trained physicians. ${ }^{10}$ While most boards inquire about disciplinary actions, which reflect 
mostly on unprofessional behavior, there is a lack of inclusion of academic performance data in the licensing application process. In addition, the lack of uniformity across all states and training pathways begs the question of how licensing boards fulfill this mission to a high degree of certainty. Implementation of a standardized VOT form for all applicants that includes academic performance metrics may help ensure that medical licensure is granted to all physicians who demonstrate academic competency during training, regardless of their degree.

This study was limited because some licensing boards have may have updated their requirements since we collected this data in 2019. This may be especially relevant to licensing boards that transitioned to an online application and perhaps revised all of their forms since the initial data collection. Future studies should be directed at examining what applicants for medical licensure are required to disclose regarding their academic performance, emphasizing state to state variability. Those results could be compared with the results of this study to determine whether the questions asked of applicants vary from those asked of PDs.

\section{Conclusion}

Although there were no major differences in the VOT forms used for USMDs and FMGs, there was wide variability between states and within individual states that offer both osteopathic and allopathic board licensure. Furthermore, the state medical licensing boards predominantly asked questions regarding disciplinary actions rather than academic performance regardless of medical degree type. Adopting and implementing a uniform VOT form across all state licensing boards, including questions pertaining to academic performance, may help ensure that medical licensure is given to physicians who demonstrate academic competency during training, regardless of their degree.

\section{Author Contributions}

All authors provided substantial contributions to conception and design, acquisition of data, or analysis and interpretation of data; all authors drafted the article or revised it critically for important intellectual content; Dr Gajewski gave final approval of the version of the article to be published; and all authors agree to be accountable for all aspects of the work in ensuring that questions related to the accuracy or integrity of any part of the work are appropriately investigated and resolved.

\section{References}

1. Buser BR, Swartwout J, Gross C, Biszewski M. The single graduate medical education accreditation system. J Am Osteopath Assoc. 2015;115(4):251-255. doi:10.7556/jaoa.2015.049

2. National Resident Matching Program, Results and Data: 2019 Main Residency Match ${ }^{\circledR}$. National Resident Matching Program; 2019.

3. Big Gains for DO Students \& Graduates in Largest Match in NRMP History. NBOME website. Published March 19, 2019. Accessed 5 February 2020. https://www.nbome.org/news/ big-gains-for-do-students-graduates-in-largest-match-in-nrmp-history/

4. Murano T, Gajewski M, Anana M, et al. Mandated state medical licensing board disclosures regarding resident performance. J Grad Med Educ. 2019;11(3):307-312. doi:10.4300/JGME-D-18-00970.1

5. Gevitz, N. The DOs: Osteopathic Medicine in America. 2nd ed. JHU Press; 2004

6. Johnson DA, Chaudhry HJ. Medical Licensing and Discipline in America: A History of the Federation of State Medical Boards. 1st ed. Lexington Books; 2012.

7. Papadakis MA, Arnold GK, Blank LL, Holmboe ES, Lipner RS. Performance during internal medicine residency training and subsequent disciplinary action by state licensing boards. Ann Intern Med. 2008;148(11):869-876. doi:10.7326/ 0003-4819-148-11-200806030-00009

8. Khaliq AA, Dimassi H, Huang CY, Narine L, Smego RA Jr. Disciplinary action against physicians: who is likely to get disciplined? Am J Med. 2005;118(7):773-777. doi:10.1016/j.amjmed.2005.01.051

9. Young A, Chaudhry HJ, Pei X, Arnhart K, Dugan M, Steingard SA. FSMB census of licensed physicians in the United States, 2018. J Med Regulation. 2019;105(2):7-23.

10. Drew C, Thompson JN. The role of state medical boards. Virtual Mentor. 2005;7(4). doi:10.1001/virtualmentor.2005.7.4.pfor1-0504 () 2020 American Osteopathic Association 